\title{
Sergio Zañartu
}

Facultad de Teología

Pontificia Universidad Católica de Chile

\section{Autenticidad de la recensión media de Ignacio de Antioquía Notas sobre discusiones recientes

Estas notas eran parte integrante de mi investigación: Ignacio de Antioquía. Reconsideración. Son publicadas aparte por problema de espacio, para aligerar el artículo anterior, pero deberían ser leídas en conjunto con ese artículo o como un apéndice de él. En mi intento de revisar lo publicado sobre Ignacio posterior a mi tesis (2), estas notas pretenden una rápida presentación directa con breve comentario de las hipótesis de Rius-Camps, Joly, Hübner y Lechner sobre la composición de la recensión media. Al separarlas del tronco principal arrastran consigo las opiniones de algunos autores, p. ej. sobre los oponentes de Ignacio, que parecía conveniente insertarlas en la discusión con Rius-Camps, etc. Por otra parte, las cosas ya dichas, y con cierta extensión, en la presentación general de los autores, p. ej. sobre el "episcopado monárquico" ignaciano, sobre fechas de composición, no se repiten ahora. Es decir, ambos artículos son complementarios.

Una etapa de los estudios ignacianos había quedado concluida a fines del s. XIX con los eruditos trabajos de T. Zahn, F. X. Funk y J. B. Lightfoot. Salvo rarísima excepción, todos aceptaron la recensión media como la auténtica (3). Pero

(1) Agradezco la generosa ayuda económica de la Dirección de Investigación de nuestra Universidad para la adquisición de artículos vía INTERNET, y a nuestra biblioteca por la compra de algunos libros y la traída de los artículos.

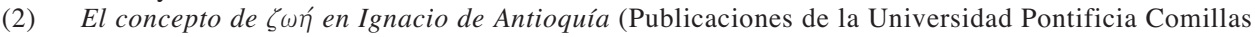
Madrid, Teología, I, 4), Madrid 1977, 294 pp. Posteriormente publiqué: Les Concepts de vie et mort chez Ignace d'Antioche, Vigiliae Christianae 33(1979)324-341; Aproximaciones a la cristología de Ignacio de Antioquía, Teología y Vida 21(1980)115-127; Aproximaciones a la eclesiología de Ignacio de Antioquía, Stromata 38(1982)243-281; La Iglesia carnal y espiritual en Ignacio de Antioquía, en E.A. Livingstone (ed.), Studia Patristica. Papers of the 1983 Oxford Patristics Conference, XVIII, 3, Kalamazoo-Leuven 1989, pp. 263-272. Estos artículos también pueden ser consultados en la página web de nuestra Facultad (www.puc.cl/teologia) bajo mi nombre en Cuerpo Docente.

En el presente trabajo, las referencias a las cartas de Ignacio se simplificarán de la siguiente manera: E (Efesios), M (Magnesios), T (Tralianos), R (Romanos), F (Filadelfios), Sm (Esmirniotas), P (Policarpo).

(3) La recensión larga sería una interpolación de la segunda mitad del s. IV, y la recensión corta, siríaca, un abreviado. Respecto a la edición crítica de la recensión media, K. Bihlmeyer establecía lo siguiente: "Bei der Feststellung des Textes ist mit Funk im allgemeinen von G im 
Weijenborg, en 1969, recomienza, por así decirlo, el ataque contra la autenticidad de la recensión media. Más adelante haré una breve referencia a este trabajo anterior a mi tesis. Y después vienen los autores arriba citados. ¿Son serias estas objeciones puestas a la autenticidad o solamente un pequeño y precipitado remezón más? Ciertamente, si leemos Ignatios en la última edición del Lexikon für Theologie und Kirche, su presentación es bastante diferente de la edición anterior en que la autenticidad de la recensión media se daba como indiscutida. Ahora, en cambio, el Lexikon dedica un largo párrafo a enumerar las opiniones contrarias, como las de Weijenborg, Rius-Camps, Joly, etc., añadiendo solo al final, que no en rara ocasión la hipótesis de la autenticidad es preferida (4). ¿Es razonable esta presentación o hay que atenerse a la recensión media de las siete cartas citadas por Eusebio mientras no se pruebe lo contrario? Una rápida referencia a algunos de los argumentos principales de los que objetan la recensión media nos mostrarán la inconsistencia probatoria de ellos. Mis observaciones al respecto, que van dentro de la general reacción contraria (5) que han suscitado los objetores, solo pretenden decir algunas obviedades o insinuar algunos de los aspectos no considerados por estos ataques. Intentar responder a cada una de ellas con una prueba científica y con la respectiva bibliografía, dada la naturaleza de los argumentos (o suposiciones) de estos autores, no tendría sentido en esta revisión bibliográfica. Para una presentación más rigurosa de mi interpretación de Ignacio, remito a mi tesis y artículos que la han acompañado.

No pequeño fue el trabajo de J. Rius-Camps, quien tuvo la osadía de publicar The Four Authentic Letters of Ignatius, the Martir (6). Comencemos observando el Apéndice, donde publica las cuatro cartas auténticas, según él. Rius-Camps considera como auténticas las cartas que aparecen escritas desde Esmirna, en las que no dice que él sea el obispo de Antioquía ni se alude a esta comunidad. La carta a los Romanos, que tiene tradición manuscrita especial (7), es la única no interpolada, porque era desconocida para el interpolador o falsario. La segunda carta es la dirigida a los Magnesios, cuyo material dividió el interpolador entre M y F, haciendo

Zusammenhalt mit L auszugehen; bei Differenzen zwischen diesen beiden Zeugen verdient L meist den Vorzug. In manchen strittigen Fällen geben die orientalischen Übersetzungen, denen eine griechische Textform des 4. Jahrhunderts zugrunde liegt, den Ausschlag...." (Die Apostolischen Väter, I, $2^{\text {a }}$ ed., Tübingen 1956, XXXVII).

(4) En cambio, W. R. Schödel en el TRE concluía: "Es spricht demnach alles dafür, dass die mittlere Rezension als das anerkannt bleiben wird, was der wissenschaftliche Konsens heute in ihr sieht: eine Sammlung echter Briefe des Bischofs Ignatius von Antiochien" (Ignatius von Antiochien, TRE, XVI (1987), 40-45, p. 40).

(5) Puede verse, por ejemplo, conclusión de C. Munier, Où en est la question d'Ignace d'Antioche? Bilan d'un siècle de recherches 1870-1988, pp. 470-484, en ANRW, II, 27, 1, pp. 359-484.

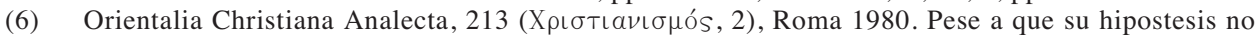
fue seguida por nadie, en 2001 Rius-Camps termina editando el texto de sus cuatro cartas auténticas en griego y con traducción catalana, seguidas de un largo comentario de cada una (Ignasi d'Antioquia. Cartes (Escriptors Cristians), Barcelona, vol. II). En el volumen I presenta el texto griego de la recensión media con traducción catalana, en el orden de cartas de la compilación que él llama policarpiana, con un largo comentario a cada una mostrando la actividad del interpolador. Este volumen va precedido de una introducción y de una buena bibliografía. En su texto griego destaca en negritas lo que a él le parece interpolado.

(7) Según J. J. Ayán (Ignacio de Antioquía. Cartas. Policarpo de Esmirna. Carta. Carta de la Iglesia de Esmirna a la Iglesia de Filomelio (Fuentes Patrísticas, 1), Madrid 1999, p. 57s), no consta que el texto griego de R no se transmitiera junto con las otras cartas. 
terminar $\mathrm{F}$ en forma parecida a $\mathrm{Sm}$. Sm y F están fuertemente interpoladas. En la reconstrucción de F, Rius-Camps suprime (8) como interpolados casi solo los numerosos párrafos, aunque sean amplios (9), que incluyan una alusión a obispos, presbíteros y diáconos (10), salvo el que se refugien en los apóstoles como en el presbiterio de la Iglesia $(\mathrm{F} 5,1)$. En $\mathrm{F}$ también desaparece la referencia a la jerarquía y a Antioquía en el párrafo sobre la pacificación de esta última (11). La tercera carta auténtica es la dirigida a los Tralianos. Pero T de la recensión media está fuertemente interpolada, y alterado el orden final. Rius-Camps, en la reconstitución que hace de esta carta repite exactamente el procedimiento usado a propósito de M y F. Y la última carta auténtica, la cuarta, es la dirigida a los Efesios, que fue dividida en E y Sm. La carta a Policarpo es espuria (12), pero la parte en plural retiene varios pasajes del final original de E. En la reconstrucción de esta carta repite el mismo procedimiento anterior, eliminando también algunas pequeñas cosas más, porque tiene que coordinar tres cartas y a ratos también el final de F (13). Así es como presenta las cartas auténticas y los trozos suprimidos en el Apéndice.

Siendo el resultado de este método embrollado y lleno de suposiciones no probadas, la eliminación de toda alusión al obispo, presbíteros y diáconos, consiguientemente de Policarpo (14) y de la parte dedicada a este en singular, al reducir seis cartas supuestamente interpoladas a tres auténticas, sería lógico que hubiera destacado más ese supuesto fundamental: la no existencia de la jerarquía tal como la describe Ignacio. Hubiera debido probar por qué bajo Trajano era imposible que existiera históricamente la triple jerarquía con su episcopado 'monárquico'. Pero él no entra en esto, sino que de paso declara que sería un anacronismo porque supone un episcopado confinado en las ciudades más importantes (no por provincias). A este propósito solo trae la afirmación de Ireneo (15) sobre Policarpo: constituido obispo en Esmirna por los apóstoles para Asia (16). La única alusión al respecto

(8) De las dos inscripciones (de M y F) hace una sola.

(9) Así se pierde mucho material valioso, como el fenómeno pneumático de Ignacio en $\mathrm{F} 7,1$. Conserva como auténticas las exhortaciones a la unión y unidad, como la de M 7, 2, etc. Pero ¿se trataría de una alabanza y exhortación a la unidad sin ningún referente jerárquico?

(10) Acepta como auténticos 'diáconos' en Sm 10, 1, pero en sentido amplio: "the only time Ignatius uses Sıákovos in the current sense of 'servant, messenger')" (op. cit., 161).

(11) También es interpolada la alusión a Policarpo obispo. Afirmará que Ignacio no conoció a Policarpo.

(12) Entre otras cosas, que el matrimonio se haga con la $\gamma \nu \omega ́ \mu \eta$ del obispo le parece un evidente anacronismo (P 5, 2) (op. cit., 165).

(13) Por supuesto que, igual que antes, desaparece Policarpo y Antioquía. Lamentablemente también desaparece todo E 20, que tiene una alusión a la jerarquía. Para nuestro autor es la cláusula con que el interpolador interrumpió la primitiva secuencia de E.

(14) "Tout se passe comme si, conscient des anachronismes patents dénoncés par la critique, convaincu de l'impossibilité de maintenir la datation traditionnelle, J. Rius-Camps avait résolu de débarrasser une bonne fois les Lettres d'Ignace de tous les passages relatifs à la hiérarchie cléricale à trois degrés -ces ajoutes étant, par définition, imputables à 'l'interpolateur'" (C. Munier, À propos d'Ignace d'Antioche, RevSR 54(1980)55-73, p. 68). También, al componer dos cartas o más en una, elimina lo atingente a Antioquía y Tróade, que corresponde a las tres últimas cartas ignacianas en el orden habitual, que él fusiona con E y M. Ch. Trevett señala alguna de las inconsistencias en que cae Rius-Camps al distribuir el material entre el auténtico Ignacio y el falsario (Anomaly and Consistency: Josep Rius-Camps on Ignatius and Matthew, VC 38(1984)165-171).

(15) Adv Haer, III, 3, 4.

(16) P. ej. op . cit., 33; 82-84. 
sería, entonces, el "obispo de Siria" en la no interpolada carta a los Romanos (17). Y en la bibliografía de Rius-Camps no aparecen citados los autores especializados en esta materia.

Sin entrar propiamente en el tema, que supone pero no trata el autor que comentamos y del que ya han aparecido muchas cosas en mi artículo anterior (18), quisiera decir ahora solo algunas obviedades a este propósito. En el N. T. ya se habla de diáconos, presbíteros y 'obispos' (19). ¿Por qué desaparecen de los escritos ignacianos que justamente están exhortando a la unidad de la comunidad? Por otro lado, en el s. II se consolida en la Iglesia el monoepiscopado. ¿No puede haberse adelantado este proceso en algunas zonas, donde se sintiera más la necesidad pastoral, o donde las Iglesias madres (fundadoras) lo irradiaran, o donde se hubiera asentado un sucesor de los apóstoles? Lo normal es que los procesos se vayan decantando, afianzando y extendiendo poco a poco. Así la "sucesión de los apóstoles", ya no itinerantes, se terminará imponiendo. Tertuliano e Ireneo hablarán de la sucesión en las Iglesias apostólicas. Policarpo fue constituido obispo por los Apóstoles, según el testimonio de Ireneo. Pero, como dice, entre otros, J. Colson, no todo el llamado 'obispo' por Ignacio sería un sucesor de los apóstoles (20). Pudo ser el primero entre los presbíteros, que en un proceso de institucionalización requerido por las necesidades pastorales de la época, las que exigían una mayor unidad, comienza a destacarse del presbiterio (21). De hecho habrá 'corepíscopos' en la Iglesia del s. IV, que no eran propiamente obispos (22). El énfasis de Ignacio en el 'monoepiscopado' pudo corresponder a un reciente mayor realce de este, al que se oponían los de tendencia herética y cismática. Igualmente lamentable es que con esta extirpación de la jerarquía de las cartas de Ignacio, nuestro autor suprime material adjunto, valioso por lo trinitario, etc., y que es coherente con lo que Ignacio dice en otros sitios. Ciertamente lo que dice Ignacio, y su obra en general, puede sorprender, pero igualmente sorprenden la teología de Pablo, de Juan, de las Odas de Salomón, etc. Sinceramente no veo nada en las cartas de Ignacio que no pudiera suceder en esa época. Hay que contar con la creatividad de los primeros tiempos, que siempre es más amplia.

Sigamos desenrollando un poco más la madeja de Rius-Camps. Este basa la selección que hace de los textos y su reconstitución en algunas 'incoherencias' que él quiere solucionar. La primera y segunda (23) es que las cartas desde Esmirna se refieren a "the church that (is) in (the province of) Syria" y en las cartas desde

(17) R 2, 2 .

(18) Ignacio de Antioquía. Reconsideración.

(19) Según Hch 20, 17 y 28, los convocados presbíteros de la Iglesia de Éfeso han sido establecidos obispos para el rebaño por el Espíritu Santo.

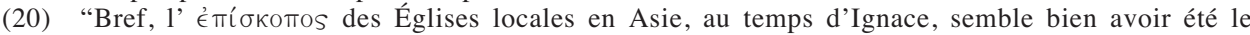
président du presbytérium, mais non un évêque proprement dit au sens actuel du terme, c'est-àdire un 'Successeur d'Apôtres'" (Les fonctions ecclésiales aux deux premiers siècles (Textes et Études Théologiques), Paris 1956, p. 239).

(21) Cf. p. ej. J. P. Meier (J. P. Meier, R. E. Brown, Antioch and Rome. New Testament Cradles of Catholic Christianity, London 1983), p. 76.

(22) Santo Tomás no destaca la diferencia entre presbítero y obispo en cuanto al sacramento del Orden, porque ambos tenían el mismo poder consagratorio respecto de la Eucaristía.

(23) Cf. op. cit., 30-34 
Tróade (24) a "the church that (is) in Antioch of Syria". Que Ignacio sea obispo de Siria, estaría confirmado por R 2, 2 (25). En cambio, F 10, 2 implica que las Iglesias cercanas tendrían obispos, como las ciudades principales de la provincia de Asia conforme a las cartas de Ignacio. Según esto, los obispos son de la ciudad y alrededores y no de toda la provincia, como sería el caso de Ignacio para Siria o como dice la referencia de Ireneo sobre Policarpo, que acabamos de ver. De esta diferencia concluye nuestro autor que lo de obispo de 'Antioquía de Siria' es un anacronismo respecto a la organización eclesiástica de los tiempos de Ignacio (26). En los hechos, valiéndose de un pequeño cambio de terminología presentado como oposición, Rius-Camps descarta como anacronismo eclesiástico la organización de la Iglesia con sus obispos locales, presentada por Ignacio. Pero quizás la oposición no sería tal. Lo primero que hay que observar es que entre una provincia y su capital puede haber una especie de ósmosis en las referencias, sobre todo tratándose de Antioquía que no es una capital cualquiera, sino la tercera ciudad del imperio, muy por encima de las otras ciudades de Siria. Por decirlo de otra forma, la provincia es la capital con sus 'alrededores', o la capital concentra la provincia. En Antioquía habían predicado Pedro y Pablo, lo que irradiaba a toda Siria, que en esa época era probablemente el principal centro de los escritos cristianos que conservamos. Por lo demás, Ignacio no dice "Iglesia de Siria", sino Iglesia que está en Siria o como traduce el mismo Rius-Camps: que está en la provincia de Siria. ¿Qué contradicción hay entre esto y que sea la Iglesia de Antioquía, capital de Siria? Es verdad que en R 2, 2,

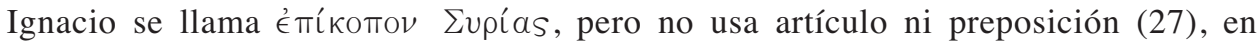

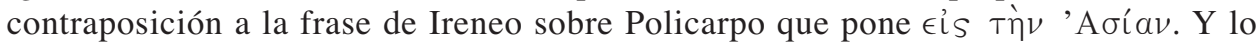
de R 2, 2 va engarzado en el venir de Oriente a Occidente; y, en este sentido, Ignacio siempre habla de venir de Siria. En Ignacio es preponderante 'Siria' (15 veces): desde ahí va (hacia Roma) y hacia allá van los delegados. ¿Por qué, pues, en las tres cartas desde Tróade se habla solo de la Iglesia que está en 'Antioquía de Siria'? Además de la razón ya dicha de que ambas expresiones pueden ser intercambiables, simplemente podría ser porque ahora especifica que esa es la Iglesia que ha encontrado la paz, o porque, dado que se trata de enviar delegados o cartas, recuerda la dirección con más precisión. Pero desde este uso no se puede concluir, con RiusCamps, que Ignacio no haya escrito cartas desde Tróade. En coherencia con su posición, nuestro autor recompondrá las cartas eliminando las tres escritas desde Tróade, en las que se menciona 'Antioquía'.

Como ya anotamos antes, hay un problema de fondo, pero que no se concluye de lo anterior. ¿Existía de alguna forma un monoepiscopado en las ciudades a las que Ignacio escribe y en otras que están más cercanas a Antioquía (F 10,2)? Esto es lo que a Rius-Camps le parece anacrónico y la única razón que trae de paso es el testimonio de Ireneo sobre Policarpo: "Constituido obispo por los apóstoles para Asia en la

(24) Notemos de paso que en las cartas escritas desde Tróade, contrariamente a las desde Esmirna, solo se dirige a Iglesias que ha conocido personalmente.

(25) Cf. R 9, 1 .

(26) También lo será que Policarpo sea solo obispo de Esmirna y no de Asia.

(27) Como dice Lightfoot, citado por el mismo Rius-Camps (op. cit., p. 31 n. 47): "the genitive denoting, not the extent of his juridiction, but the place of his abode". 
Iglesia de Esmirna" (28). Pero suponiendo que Ireneo quiere señalar una función para toda la provincia del Asia, se trataría en este caso de un sucesor de los apóstoles, que hasta podría 'supervisar' (e influenciar) a los otros obispos' de la región, como sucederá posteriormente con los metropolitas y patriarcas, en la línea de irradiación de esas Iglesias. Situación parecida podría ser la de Ignacio en Siria. Ciertamente, todo lo que sucedía en Antioquía repercutía en las demás Iglesias de Siria. Baste con estas simples ideas, porque no es el caso tratar de cómo fue la implantación del monoepiscopado en las Iglesias, dado que en ese tema nuestro autor no entra.

La tercera incoherencia señalada por nuestro autor, es que Ignacio, siendo obispo (R 2, 2), se declara $\sigma u ́ v \delta o u \lambda o s ~(29)$ de los diáconos, es decir, diácono (30). RiusCamps elige lo primero (es obispo) y terminará no reteniendo como auténtico ningún texto en que se hable de 'diácono' en sentido técnico. Observemos que entre la declaración de ser $\sigma u ́ v \delta o u \lambda o s$ con los diáconos y ser uno de ellos, hay un salto lógico. De hecho, Rius-Camps trae otras explicaciones que se han dado de esa expresión y que no le satisfacen: humildad, la experiencia de estar encadenado, la especial relación entre el obispo y los diáconos, el uso de estos términos en Col 1, 7 y 4, 7. Con todo, no trae el texto clave de R 4, 3 (no interpolado según él): "No os mando como Pedro y Pablo;

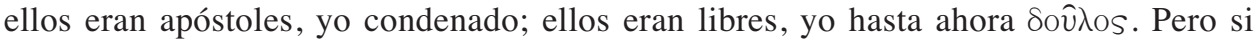
padezco, llegaré a ser liberto de Jesucristo y resucitaré libre en él". Este texto no tiene nada que ver con los diáconos. Ignacio se siente siervo en el camino a su martirio. Igualmente no se siente digno de la Iglesia de Siria, siendo el último de sus fieles (31). Se considera un aborto. Y respecto a su martirio, está ansioso. Se percibe bajo peligro $(\mathrm{E} 12,1)$. Que los romanos no le hagan caso si les suplica cuando esté con ellos, sino que hagan caso a lo que ahora les escribe $(\mathrm{R} 7,2)$, diciendo que quiere morir. Esta inseguridad que muestra de paso respecto a su enfrentar el martirio, podría quizá ser otra cara del deseo apasionado por este. Pero volviendo a la indignidad respecto a su Iglesia de Antioquía de Siria, no sería extraño que haya sido acusado a la autoridad romana a raíz de un conflicto interior de la comunidad cristiana (32) -en el que él

(28) Y tuvo sucesores, según el mismo texto de Ireneo. Según G. J. M. Bartelink, refiriéndose al argumento de Rius-Camps, “...does not seem valid as it is more probable that it is a specification of Smyrna (“in Asia')" (VC 35(1981)184). "R. -C. ne fait pas même allusion à une autre interprétation beacoup plus simple et qui est celle de tout le monde: $\epsilon i s+a c c .$, depuis toujours en grec,

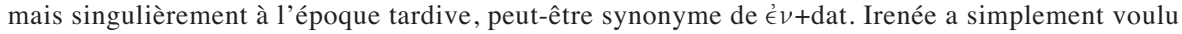
rappeler, lui qui écrit en Gaule, que Smyrne est en Asie et son traducteur latin ne s'y est pas trompé" (R. Joly, Le dossier d'Ignace d'Antioche (Université Libre de Bruxelles. Faculté de Philosophie et Lettres, 69), Bruxelles 1979, p. 123).

(29) E 2, 1; M 2; F 4; Sm 12, 2.

(30) Op. cit., 34-38.

(31) Cf. E 21, 2; T 13, 1; R 9, 2; Sm 11, 1. Véase M 14.

(32) Según $1 \mathrm{Cl} 5$, 2ss, Pedro y Pablo murieron en Roma por envidia. Basado en el voluntario morir de R 4, 1 y Sm 4, 2, Rius-Camps llega a afirmar: "The only plausible explanation is that Ignatius has delivered himself over to the authorities spontaneously as wholly responsible for the uproar" (op. cit., 142). Pero él está condenado como cristiano (E 1, 2; 3, 1; T 1, 1; R 1, 1). Sobre la crisis interna de Antioquía, puede verse, p. ej., la hipótesis de C. P. H. Bammel (Ignatian Problems, JThS 33(1982)62-97, pp. 78s; 87-89, etc.). Según M. Isacson respecto al 'ethos of the sender' (Follow Your Bishop! Rhethorical Strategies in the Letters of Ignatius of Antioch, p. 322, en Jostein Adna (ed.), The Formation of the Early Church (WUNT, 183), Tübingen 2005, pp. 317340), "Ignatius' self-description as 'not being someone' is not unique feature, but a rhetorical and epistolary convention in Early Christian literature". 
podría tener responsabilidad-, porque esta Iglesia, cuando él ya está en Tróade, no solo ha recobrado la paz, que puede festejar con otras Iglesias, sino que ha sido restablecido su propio $\sigma \omega \mu \alpha \tau \in \hat{\imath} \mathrm{O} \nu$, su propia grandeza; ha llegado a puerto (Sm 11, 2s)

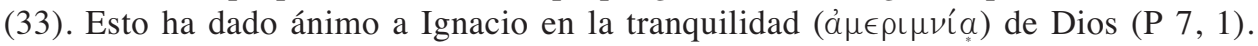
Todo lo anterior concuerda con que Ignacio se sienta $\delta \circ \hat{\jmath} \lambda o s$, independientemente de llamar consiervos a los diáconos (34).

Ignacio muestra su aprecio por los diáconos comparándolos con Jesucristo (35). Debe haber estimado mucho a los diáconos (36) que lo servían en su prisión. Así desea que Burro permanezca con él (E 2,1), y de hecho Burro lo acompañará a Tróade (37). No es de extrañar, pues, que a estos, en cierta forma compañeros en la prisión, los llame consiervos (38), sintiéndose él condenado y siervo. Están en el mismo servicio de Dios. Pero de llamarlos así no se deduce que él mismo Ignacio sea diácono.

La cuarta incoherencia, según nuestro autor (39), es el final de la carta a los Efesios, en que promete una segunda carta, que nunca escribió (40). La explicación que se ha dado es la repentina partida de Tróade (4). Esto no satisface a RiusCamps. Por mi parte, además que no es necesario explicar por qué no se cumple una promesa condicionada, más aún cuando se está prisionero y se es obligado a proseguir el viaje repentinamente, quisiera hacer alguna observación. Ignacio en sus cartas, fuera de acentuar la carne y divinidad de Cristo, y su pasión-resurrección, muy escasamente habla de la vida de Jesús (42). La unción en la cabeza en E 17 es incidental, referente a la incorruptibilidad de la Iglesia de la que no hay que ser arrebatado por el mal olor de la enseñanza hereje. Entonces entra a hablar rápidamente de la economía de Dios respecto al nacimiento de Cristo y su bautismo. Probablemente se trata de objeciones de los adversarios (43). A este propósito se explaya en E 19, pasaje judeocristiano que tanto llamó la atención de H. Schlier (44). Y entonces, habiéndose salido de su tema habitual, interrumpe, remitiendo a un segundo escrito, en que proseguiría explicando la economía de Dios, sobre todo si se le revela la unidad de los efesios en la fe, en la eucaristía y en la sujeción al

(33) Ignacio, por lo demás, no muestra ninguna hostilidad al Imperio que lo va a martirizar.

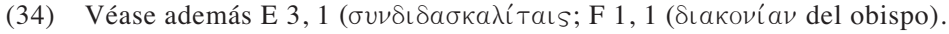

(35) T 3,1. A los diáconos se les ha encomendado el servicio de Jesucristo (M 6, 1; cf. T 2, 3; Sm $12,1)$.

(36) Son dulcísimos para él (M 6, 1).

(37) Mediante él escribirá a Filadelfios y Esminiotas (F 11, 2; Sm 12, 1). También sirve a Ignacio el diácono Filón de Cilicia y Reo Agatopodo, que lo sigue desde Siria (F 11, 1; Sm 10, 1). Burro es

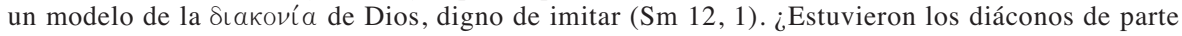
de Ignacio en algún conflicto con los presbíteros de Antioquía?

(38) Usando una fórmula que encontramos en Col 1, 7 y 4, 7. De hecho llama consiervos solo a diáconos con los que tuvo contacto en su camino de prisionero.

(39) Op. cit., 38-40.

(40) E 20,1.

(41) P 8,1.

(42) P. e. T 9, 1; Sm 1, 1. Puede verse S. Zañartu, Aproximaciones a la cristología de Ignacio de Antioquía, Teología y Vida 21(1980)115-127, pp. 118s.

(43) Cf. Sm 1, 1. La unción también podría ser un texto usado por los adversarios.

(44) Religionsgeschichtliche Untersuchungen zu den Ignatiusbriefen (BZNW, 8), Giessen 1929. Puede verse la reciente opinión de H. F. Stander respecto a las estrofas del himno (The Starhymn in the Epistle of Ignatius to the Ephesians (19: 2-3), VC 43(1989)209-214). 
obispo. Ignacio solo en estos párrafos alude a una explicación de la economía de Dios (45). Y eso lo conecta con una preparación especial de los Efesios, que él conocería por revelación del Señor. Por lo tanto, explicar la economía de Dios, como lo hace en E 19, no está en lo ordinario de Ignacio, según lo que conocemos (46). Y justamente, diciendo que continuaría la explicación en otra ocasión, Ignacio cierra su carta y termina. Sería una forma brusca de terminar la digresión y poder concluir la carta. Supuesto esto, no es tan extraño que no haya escrito una segunda carta.

La quinta incoherencia es que Ignacio combate dos tendencias, una predominantemente doceta-gnóstica (E, T, y Sm), y la otra judaizante (M y F) (47), que no insiste en la circuncisión (48). Contra los partidarios de un sincretismo judeognóstico, Rius-Camps trata de diferenciar las dos tendencias, aunque Ignacio las etiquete de la misma manera, lo que a lo más prueba que eran igualmente peligrosas (49). Así se empeña en suprimir las resonancias docetas en algunos textos de M y F, pero no me convence que no la haya en M 11 (50). Por otro lado, me parece que en Sm 1, 2; 5, 1 y 7, 2, carta catalogada como antidoceta, se podría apuntar a un problema judaizante (51). La base de Rius-Camps es que no habría otro testimonio de una herejía judaizante doceta (52). Pero si al judaísmo ortodoxo

(45) La otra alusión a la economía (del Señor) está en E 6, 1.

(46) Véase también T 5, 1.

(47) "In these two letters he refrains from speaking of Jesus as $\theta \in$ ós", anota Bammel (op. cit., 88).

(48) Op. cit., 40-51. Interpreta el é $\kappa \hat{\epsilon} \theta \in \nu$ de E 9, 1, como misioneros docetas provenientes de Siria.

(49) De hecho se muestra más gentil en su polémica contra los judaizantes.

(50) Y habría que ponderar también la 'evanescente' insinuación de F 5, 1.

(51) Recordemos que Ap 2, 9 y 3,9 también señalan un fuerte problema judaico en Filadelfia y Esmirna. El Ap no tiene carta a los Magnesios.

(52) Puede leerse el artículo de M Goulder sobre el ebionismo: A Poor Man's Christology, NTSt 45(1999)332-348 (cf. Id., Ignatius' “Docetists”, VC 53(1999)16-30). Este autor se pronuncia por el ebionismo como adversario de Ignacio, una sola herejía (ib., 338-341). C. K. Barrett parece inclinarse por una sola herejía, destacando círculos de simpatizantes del judaísmo (no ortodoxo), que tienen dificultad con la circuncisión y que hubieran pasado al cristianismo, rechazando la interpretación cristiana del mesianismo y expresándose con algunos elementos gnósticos (Jews and Judaizers in the Epistles of Ignatius, p. 233ss, en R. Hamerton-Kelly, R. Scroggs (ed.), Jews, Greeks and Christians in Late Antiquity. Religious Cultures in Late Antiquity. Essays in Honor of William David Davies (Studies in Judaism in Late Antiquity, 21), Leiden 1976, pp. 220-244). U. B. Müller cree que la herejía es un solo conjunto y llega a sostener que de una cristología angélica, cuyos rasgos ya se traslucían en el Ap, ha derivado un docetismo estricto (Zwischen Johannes und Ignatius. Theologischer Widerstreit in den Gemeinden der Asia, ZNTW 98(2007)49-67, pp. 61-67).

J. Speigl (Ignatius in Philadelphia. Ereignisse und Anliegen in den Ignatiusbriefen, VC 41(1987)360-376) destaca la experiencia profética de Filadelfia. "Die Lehrabweichungen und Häresien, die in den Briefen genannt werden, scheinen also grossenteils auf die Erlebnisse zurückzugehen, die Ignatius in Philadelphia mit Häretikern und Schismatikern hatte" (ib. 369). "Darum war das grosse Anliegen des Ignatius die ortskirchliche sonntägliche bischöfliche Eucharistieversammlung. Insofern wird die Opposition gegen den Bischof von ihm in grosser Nähe zur manifesten Häresie gesehen. Sein eigener Prophetenruf ging nicht auf die Klärung einer Glaubensfrage sondern auf die Mahnung zur Sammlung zur Einheit mit dem Bischof, weil diese alle Spaltung und Häresie überwinden konnte oder im anderen Fall offenkundig machte" (ib., 371).

Entre muchos que defienden que las herejías son dos, se cuenta a P. J. Donahue, Jewish Christianity in the Letters of Ignatius of Antioch, VC 32(1978)81-93; C. T. Brown., The Gospel and Ignatius of Antioch (Studies in Biblical Literature, 12), New York 2000, cap. 5 ; C. Trevett, A study of Ignatius of Antioch in Syria and Asia (Studies in the Bible and Early Christianity, 29), Lewiston, N. Y. 1992, cap 5. C. Trevett sugiere que había en Siria una oposición carismática de 
podría repugnar, en cierto sentido, una herejía doceta, no así al heterodoxo. En mi opinión, la herejía reflejada en las cartas de Ignacio sería una sola, aunque revista matices diferentes en las diversas comunidades (53), y va muy ligada a una actitud cismática (54). Sin embargo, ¿adónde va todo esto? Porque, en el caso que hubiera dos tendencias bien demarcadas, esto no es base lógica positiva para juntar las dos cartas antijudaizantes en una sola, etc. La sexta anomalía es el comienzo de Sm y

profetas y maestros, independiente de docetas y judaizantes, a la concepción monoepiscopal de Ignacio. Ignacio nunca fundamenta su autoridad en ser obispo (Prophecy and Anti-Episcopal Activity: a Third Error Combatted by Ignatius?, JEH 34(1983)1-18). "In the language of this defense of silence, on theological and typological grounds, there is discernible something of the divide between Ignatius and his opponents and between their view of the church and office and his own" (ib., 17).

J. L. Sumney (Those Who "Ignorantly Deny Him": The Opponents of Ignatius of Antioch, JECS 1(1993)345-365, pp. 364s) concluye así su análisis minimalista de Sm, F y M: "docetists in Smyrna and those who see different ties between Judaism and Christianity than Ignatius does in Philadelphia. There is no evidence in Philadelphians that the opponents require any aspect of Jewish practice. Instead, the central issue is the interpretation and authority of the Hebrew Scriptures.... We located no opponents as such in Magnesia. While Ignatius is concerned about insufficient submission to the bishop and the relationship of Christianity to Judaism, we found no on-going advocacy of the views he opposes and no sustained opposition to his views... As the office changed, some did not want to surrender their former freedoms, but this does not mean that they quickly formed an opposition party. Taking each letter on its own, we find no evidence of a combination of docetism with elements of Judaism: the opponents at Philadelphia and Smyrna are separate and distinct groups... Thus even Magnesians is not good evidence for a mixture of Judaizing and docetism, as it is sometimes claimed to be... Since each of these letters addresses different problems, they are evidence for the situation in the cities to which they were sent rather than for the situation at Antioch".

(53) "It may well be that the two tendencies attacked by Ignatius were not entirely separate. The Docetics may have attempted to infiltrate the Judaizing groups as well as those friendly to Ignatius and they may in turn have picked up ideas from them. Both groups may have spread superfluous 'strange teachings', and there may well have been objectionable features shared by the two groups" (Bammel, op. cit., 83). Cf. ib., 81ss. Objetando la tardía época de composición de Joly (en torno al 165), con razón arguye Bammel: "If the autor of the letters was acquainted with the fully developed heretical groups flourishing in the seventh decade of the second century it is extraordinary that he refrains from attacking any of theirs characteristic features and confines himself to a general anti-Docetic and anti-Judaizing polemic. The accounts of the anti-heretical writers assign an important part to Antioch in the development of Gnosticism, which makes it likely that Ignatius would indeed have been in contact with Gnostic ideas at the date traditionally assigned to him" (ib., 75).

(54) A este respecto no está de más lo que concluye W. R. Schoedel (Polycarp of Smyrna and Ignatius of Antioch, en $A N R W$, II, 27, 1, 272-358, p. 304): "In all this, it is well to remember Moffatt's urging to remain alert to the circumstances of each letter and to recognize that opposition may sometimes have arisen also for non-theological reasons. Meinhold has adopted just such an attitude with the result that the Judaizing and Gnosticizing opponents have been relegated to minor roles. The major conflict, he thinks, was between pneumatics and representatives of order. Thus Ignatius defends bishops without charisma by interpreting their silence in Gnosticizing categories".

Según K. R. Morris ("Pure Wheat of God" or Neurotic Deathwish?: A Historical and Theological Analysis of Ignatius of Antioch' Zeal for Martyrdom, Fides et Historia 26(1994)2441) de la centralidad de la unidad deriva el combate de Ignacio contra los opositores, como los llamados 'docetas', que la pueden romper. Así exagera diciendo: "The most we should conjecture is that Ignatius's opponents were preoccupied with esoteric theologies that had the potential effect of moving the church's focus off of Christ's passion and resurrection... Ignatius's seemingly anti-docetic rhetoric stemmed from his concern to keep the church's focus on the fundamentals of the faith, and thereby preseve the churches' unified witness, rather that from a desire to correct specifically docetic teaching" (ib., 37). 
el final de E. El comienzo de Sm, si se omite la inscripción, es una carta abrupta en que no se hace referencia a la recepción de Ignacio en Esmirna ni a su obispo (55), presbíteros y diáconos. Pero ¿era necesario que lo hiciera en ese comienzo? A nuestro autor le parece que la condición, puesta en E 20, 2, corresponde a la alabanza de Sm 1, 1 (56). A mí más bien me suena ese comienzo como una captación de benevolencia, como lo hace otras veces, tocando justamente temas centrales de lo que suele decir a las cinco Iglesias de Asia Menor. De ahí cierta coincidencia entre Sm 1 y lo prometido en E 20. Esta coincidencia lleva a decir a nuestro autor que E 20 es un deliberado resumen del interpolador respecto al pasaje de Sm, lo que lo lleva a pensar que Esm es la otra carta prometida a los Efesios o ambas eran una sola primitivamente. Esta última será la hipótesis que seguirá. Así ha soldado lo que llama la interrupción súbita de Ef con el supuesto comienzo abrupto de Sm. Llevado de esta audaz imaginación, presenta el texto ensamblado, que a mí me parece demasiado repetitivo en algún aspecto. Con tan débil base, Rius-Camps ha tomado tijeras para cortar, componer y desechar (57). Llegado a este punto, no vale ya la pena seguirlo más allá con cierto detalle sino que solo enumeraré algunas de las cirugías que hace a la recensión media y que pone a continuación.

Nuestro autor, habiendo creído desenmascarar la táctica del supuesto interpolador, se aplica entonces, con la misma 'logicidad', a descubrir anomalías en el comienzo de F, para saltar luego a que debió existir una sola carta antijudaizante que el interpolador habría dividido en dos ( $\mathrm{M}$ y F), donde se repiten expresiones claves. Por otra parte, Sm 10s. y 13 serían la primitiva conclusión de E, adaptada a un nuevo contexto; la conclusión de F 10 sería una imitación de Sm 11, y F 11, 1 una copia de Sm 10, 1. Rearmando las cartas, suprime M 13.

Después de todo esto, da por establecido que Ignacio pasó a través de Éfeso viniendo desde Siria por mar y sería probablemente embarcado en Esmirna para Roma. Los cristianos nombrados en la despedida de Sm, serían de Éfeso. Finalmente le toca el turno a P. Elimina todo lo dirigido a este en singular, a quien no conoció, aunque estuvo en Esmirna desde donde escribió. Lo dirigido en plural a la comunidad de Esmirna sería, en su mayor parte, la conclusión original de E. Los saludos personales en E habrían sido transferidos a Sm y P. El número 13 de la carta de Policarpo a los Filadelfios sería una interpolación para autentificar la colección de cartas ignacianas, en las que se incluye P y Sm (no R, ignorada por el interpolador). No conociendo a Policarpo ni nombrando a Juan, Ignacio podría haber escrito entre el año 80 y el 100. Así nuestro autor eliminó Tróade con sus cartas y, casi sin decirlo, va eliminando todos los pasajes en que se alude a la

(55) Aunque en toda la carta no se nombre a Policarpo por su nombre, le está enviando una carta personal, donde van también saludos personales a otros de su comunidad, complementarios a los del final de Sm. Respecto a nombrar obispos, presbíteros y diáconos por su nombre en otras cartas, fuera de Pol, Ignacio solo nombra a los que han venido a verlo o están acompañándolo en el lugar desde donde escribe las cartas, desde Tróade en el caso de Sm.

(56) Las construcciones binominales, que destaca el autor en los dos trozos, me parecen frecuentes en el lenguaje de Ignacio.

(57) Así trata de evitar, además, algunas repeticiones entre las cartas sin considerar que, tratándose de cartas cortas de un prisionero sobre asuntos parecidos, este debería repetirse. 
Jerarquía. Persiguiendo de esta manera al supuesto astuto (58) interpolador, terminó 'interpolando' a Ignacio (59).

Obviamente que en la parte segunda de su trabajo, estudiando el material que consideró añadido por el interpolador, encuentra que su preocupación básica es la organización jerárquica (60) y esto lo extiende a otros pasajes similares. Al final de la parte tercera, estudio sistemático comparativo del auténtico Ignacio y el interpolado, anota nuestro autor que el interpolador distorsiona la eclesiología arcaica de Ignacio. Esta estaba centrada en Jesús el Mesías, en su real presencia por la eucaristía y la profecía en la comunidad. El interpolador hace desaparecer esta dimensión horizontal, polarizando hacia la persona del obispo, único representante de Dios. El tono pasa del exhortativo ignaciano al autoritativo (61).

Me parece lamentable la confusión creada. En conclusión, no convencen sus argumentos contra la autenticidad de la recensión media y, por tanto, hay que atenerse a ella (62), mientras no se pruebe lo contrario. Si hubiera una línea de duda

(58) Interpola bastante pasajes poniendo o insinuando siempre las mismas ideas y tratando de disimular, p. ej. llamaría 'obispo' a algunos, cuyos nombres ya aparecían en las cartas. "Le procédé méticuleux du faussaire qui consiste à répartir la matière, les phrases et les mots des lettres authentiques dans un nouveau corpus est-il pensable en dehors des habitudes de travail de la critique moderne? Le pseudo-Ignace du quatrième siècle avec sa recensión longue, nous donne un tout autre modèle d'interpolation" (R. Bodenmann, RHPhR 62(82)295).

(59) Se puede leer con provecho, entre otras, la recensión de C. Kannengiesser en RSR 67(1979)599604 y la de J. A. Fischer en ThRev 77(1981)119-122.

(60) P. ej. escribe en p. 240: "In all these we observed the same basic preoccupation: to settle definitely the vertical organization of the church (bishop, presbytery and deacons -community), by availing himself of the authority of the matyr Ignatius, to whom he has assigned the rank of deacon. Thus he corroborates the basic thesis of his system, namely obedience to the bishop as Jesus Christ to the Father, according to the pattern of the deacon and martyr, Ignatius of Antioch". El interpolador, de mitad del s. III, se habría inspirado en la Didaskalia. En p. 221, nuestro autor resume el paralelismo entre las dos obras de la siguiente manera: "Not satisfied with this, the forger has recourse to symbolism, to confirm his perfect verticalism: a) The bishop in God's place; b) The prebyters or the presbitery are a figure of the Apostles or the Apostolic college; c) The deacons are like Jesus Christ; d) The community, like the church. The models of submission are the church submitted to Jesus Christ and Jesus Christ submitted to the Father. Besides, in the Didascalia there are similar correspondences: a) Bishop/God; b) Deacon/Jesus Christ; c) Deaconess/Holy Spirit; d) Presbyters-presbytery/Apostles-Apostolic college; e) Widows-orphans/Altar; f) Community/Church". Además coincidirían en alguna expresión como: no hacer nada sin el obispo $(i b ., 238 s)$. El interpolador de Ignacio podría ser un obispo de Filadelfia. "The forger is obsessed by a type of hierarchical organization of the church, in order to avoid divisions and disunion" (ib., 241). Comenta Fischer (op. cit., 120s): "Es ist schwer zu verstehen, dass ein Kleinasiate in der Mitte des dritten Jh.s zur Sicherung seines Monepiskopats zu solch weitgehenden, im Detail raffinierten Verfälschungen der authentischen Ignatianen und zur Konstruktion eines erweiterten Briefkorpus unter dem Namen von Ignatius sowie zur Erfindung von Polykarp, 1 Phil gegriffen haben soll. Im dritten Jh. war der monarchische Episkopat doch nichts neues mehr, gerade auch nicht in Kleinasien".

(61) Op. cit., 337; 341. "If we look at content, the Ignatian exhortation aims exclusively at achieving the unity of the community with Jesus the Messiah or to avoid its withdrawal from Jesus through adverse propaganda, as also to reach his personal objective eluding all kinds of obstacles. The interpolator polarizes it above all into submission of the community to the bishop" (ib., 343).

(62) "Ces anomalies sont-elles vraiment des anomalies?... On peut donc se demander si les anomalies dénoncées ne sont pas exploitées d'une façon trop rigide contre l'unité d'auteur et si on n'en trouverait pas d'identiques dans les oeuvres dont l'origine est absolument claire" (H. Crouzel, BLE 83(1982)61s). "Unfortunately this bold thesis -however attractive its anti-authoritarianism may seem in the modern world- rests on a forced reading of a few odd expressions in the letters and a highly subjective identification of dislocations in the text. Joly has rightly characterized the 
interna a seguir, sería la insinuada en mi trabajo sobre la diferencia, por el contenido, entre R, P y las otras cinco cartas (63).

Si Rius-Camps se centró en la crítica interna, R. Joly lo hace en la externa (64). Reúne, contra el estudio de Lightfoot, todos los argumentos que encuentra en contra la autenticidad de las cartas ignacianas para concluir que el falsario escribió después del martirio de Policarpo, en un medio esmirniota, entre los años 165 y 168. Rechazadas las diversas explicaciones de las tensiones o anomalías que presenta la carta de Policarpo a los Filipenses, Joly opina que el párrafo 13 de esta es una interpolación para autentificar las cartas de Ignacio (65). Ignacio sería un mártir de Filipo (cf. Policarpo, Flp, 9), cuyo nombre habría tomado el falsario para construir las cartas. A Joly le parece que las singularidades del escenario (66) son contrarias a la autenticidad de las cartas ignacianas. A favor de una época tardía estaría cierta dependencia de la Doctrina Petri y de Hermas, y que introduce vocablos que serían posteriores en el uso

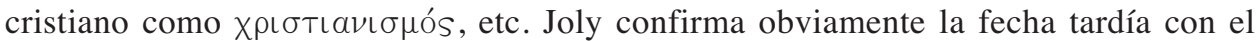
tema del episcopado monárquico y con el de los contactos gnósticos (67), aunque en esto último reconozca que lo combatido por Ignacio es particularmente el docetismo. A propósito de la influencia del IV Macabeos, añade que su estilo es de gabinete y no de prisionero. Considerando otros testimonios antiguos, dice que la datación tradicional no reposa en nada serio y que provendría de Julio el Africano (68). Al final, en una frase retórica, deja el juicio al lector, después de afirmar que los partidarios de la tradición jamás pudieron probar ni la autenticidad de las cartas de Ignacio ni la imposibilidad de un fraude. Se puede agradecer a Joly que haya vuelto a reunir los diversos argumentos en contra la autenticidad (69) y que, al exponerlos, una vez más deje de

construction as a house of cards" (Schoedel, Polycarp, 291s). Esto no quita que el libro de RiusCamps contenga valiosas observaciones sobre diversos pasajes de Ignacio. A esto pudo ayudar el tener una mirada diferente.

(63) Según C. P. H. Bammel (op. cit., 63), R y P son las menos interpoladas en la recensión larga.

(64) Le dossier d'Ignace d'Antioche (Université Libre de Bruxelles. Faculté de Philosophie et Lettres, 69), Bruxelles 1979.

(65) ¿Tan deficiente es el interpolador para dejar abierta la aparente incoherencia en que por un lado se lo supone ya mártir (Flp 9) y por otro en camino al martirio? Ayán, en su edición (Ignacio de Antioquía), anota respecto a la frase latina del final de Flp 13: "Literalmente 'y de los que están con él'. El traductor latino ha traducido como si Ignacio aún viviese. En el texto griego se debía

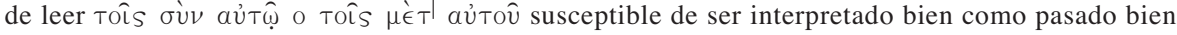
como presente. El traductor latino se equivocó al traducir en presente, como también lo hizo anteriormente en el cap. 9, 1 donde Tốs '̇ं $\xi \hat{v} \mu \hat{\omega} \nu$ es traducido como 'qui ex vobis sunt', cuando el contexto impide tal sentido". Véase Schoedel, Polycarp, 277. "Theories of interpolation still have theirs defenders today, but a mayority of scholars regard the work of Th. Zahn and J. B. Lightfoot as decisive in establishing the authenticity of these materials", opina Schoedel respecto a la carta de Policarpo a los Filipenses (Polycarp, 277).

(66) Como el hecho de ser conducido a Roma para el martirio, no tener una carta a los antioquenos, no nombrar a sus compañeros de condena, ser custodiado por demasiados soldados, no nombrar a Policarpo en Sm, ni al obispo de Filadelfia en F.

(67) Respecto al texto crítico de M 8,2, vuelve a las fuentes GL, que Lightfoot supuso interpoladas (cf. op cit., 71-73). Pero es el texto facilior.

(68) Como en muchas otras cosas, su hipótesis sobre la actitud de Polícrates respecto a Ignacio no parece seria.

(69) "We have here an excellent summary of the traditional arguments and some fresh points as well" (Schoedel, Polycarp, 292). 
manifiesto su inconsistencia probatoria frente a la afirmación tradicional. Varias de las anomalías que Joly detecta en lo de Ignacio y con las que arguye, ya habían sido enumeradas a propósito de Rius Camps. Al respecto y con sensatez, responde C. P. H. Bammel que muchos problemas se deben a nuestra ignorancia respecto a las comunidades cristianas de esa época (70). Y respecto al episcopado 'monárquico' tenido como anacrónico, anota el mismo Bammel que, mientras más se retrace su origen, más dificultad habrá para explicarlo (71). “¿Dónde están los otros testimonios literarios de la lucha de los obispos por imponer su poder 'monárquico' frente a estructuras de gobierno más colegiales, heredadas del s. I?", se pregunta Kannegiesser (72). Señala también este último autor la conveniencia de un nuevo Lightfoot, que tome en consideración el cambio de espíritu acaecido y las nuevas adquisiones realizadas para dar a los problemas ignacianos su verdadera dimensión actual (73). A mi modo de ver, un buen aporte a este camino es el balance de Munier, reseñado en mi otro artículo sobre Ignacio reconsiderado.

El trabajo de R. Weijenborg (74) fue anterior y no entra en el período revisado en este artículo. Por eso solo lo evoco rápidamente. Va comparando la recensión larga de E con la media y concluye extrañamente que la media depende de la larga. Como la larga es fechada por el 360, la media es posterior. Por tanto, las alusiones de Eusebio que utilizaren la recensión media podrían haber sido posteriormente

(70) Op. cit. 79. Por tanto, no basta con decir que no habría otro testimonio de esa época o tratar de interpretar los llamados 'silencios'. Respecto a estos frecuentes argumentos ex silentio, opina $\mathrm{H}$. Crouzel: “C'est un genre d'arguments qui comporte souvent une certaine dose d'arbitraire, une certaine incapacité du critique à se mettre dans la mentalité psychologique ou historique de l'auteur. On peut toujours se demander si les manques de cohérence découverts ne parlent pas plutôt pour l'authenticité que pour l'action d'un faussaire" (BLE 83(1982)60).

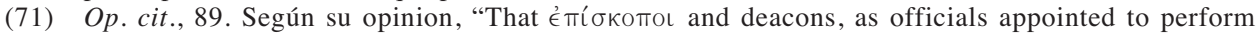
specific administrative and financial functions, are different in origin from presbyters or elders is apparent and is brought out clearly by Ignatius' picture of prebyters as a collegiate body. Ignatius' analogy (véase M 6,1) can most naturally be understood if one assumes that it reflects the situation of a community in which bishop and deacons were superimposed on a ministry with prebyters only or vice versa, or alternatively the amalgamation of two communities, the one possessing bishop and deacons, the other prebyters alone" (ib., 93). "If Ignatius and Polycarp were the leaders of a Johannine party and none the less fail to mention John, the reason may be attributed to the existence of one or more 'Cerinthian' Docetic splinter groups which had broken off from that party and were bringing it into discredit" (ib., 96).

(72) “Où sont les autres témoignages littéraires de la lutte des évêques désireux d'imposer leur pouvoir 'monarchique' face à des structures de gouvernement plus 'collégiales', héritées du 1er siècle?" Y continúa: "Il faut bien que le faussaire des Lettres d'Ignace, qui obsède un RiusCamps ou un R. Joly, finisse par trouver son lieu polémique et doctrinal au grand air des Eglises du IIe siècle, dans des contextes vérifiables. On connaît à cette époque les tensions entre communautés judéo-chrétiennes et Eglises à majorités pagano-chrétiennes, entre milieux gnostiques et autorités non-gnostiques au sein des chrétientés (), entre quatordécimans et partisans de la fête de Pâques dominicale; mais on ne connaît pas de développement littéraire et doctrinal qui aurait été suscité en ce temps-là par une polémique directement liée à des structures épiscopales en conflit, malgré tous les abus de pouvoir dont les chefs d'Eglise ont alors pu se rendre coupables, selon les lieux et les personnes" (Bulletin de théologie patristique. Ignace d'Antioche et Irénée de Lyon, RSR 67(1979)599-623, p. 607). Como muestra de la crítica general respecto a Joly, puede verse su refutación de Ayán (op. cit., 64-74).

(73) Ib., 608. Puede verse las detalladas observaciones de G. Pelland, "Le Dossier des lettres d'Ignace d'Antioche”: à propos d'un livre récent, Science et Esprit 32(1980)261-297.

(74) Les lettres d'Ignace d'Antioche. Étude de critique littéraire et de théologie, Leiden 1969. 
interpoladas (75). Evagrio el Póntico, inspirándose en la sátira de Luciano de Samosata (76), podría haber escrito las cartas de Ignacio (77). La razón principal para que a partir de la recensión larga se hiciera la media, habría sido la de perfeccionar la expresión literaria y darle un carácter más arcaico. Obviamente, la hipótesis de Weijenborg no ha sido recibida (78).

Después del rechazo generalizado de las hipótesis de estos tres autores sobre inautenticidad o adulteración de la recensión media, parecía que hubiera vuelto la calma en torno a ella. En 1993 concluía C. Munier su balance (79), ya mencionado, con las siguientes palabras: "Según la opinión general de los historiadores y patrólogos que se han pronunciado hasta el presente, está fuera de lugar el abandonar, en vista de los trabajos de Weijenborg, Joly y Rius-Camps, las conclusiones establecidas por los filólogos del siglo XIX" (80). Pero han surgido posteriormente, al menos, dos nuevos opositores, Hübner y su discípulo Lechner (81). La tesis central de R. M. Hübner (82) es que las cartas de Ignacio presuponen conocida la teología

(75) En la primera parte había tratado de probar que no utilizaba la recensión media. En esa parte, después de pasar revista a los nueve testimonios de Lightfoot aceptados por Harnack, concluía afirmando con decisión: "A la fin de notre analyse des témoignages dont quelques-uns semblent attester l'existence de notre (recension) M(oyenne) avant 360, nous constatons n'en avoir rencontré aucun absolument certain en faveur de cette recension" (op. cit., 31).

(76) De morte peregrini.

(77) "Plusieurs ressemblances nous invitent donc à voir dans Lucien de Samosate l'une des sources majeures du recueil original des lettres ignatiennes et dans celui-ci un ouvrage apologétique réussi à merveille" (op. cit., 401). Al final dirá: "Si 1'auteur de la recension L(ongue) des lettres ignatiennes s'identifie, comme on l'admet généralement, avec celui des Constitutions Apostoliques, il est assez probable qu'elles furent soumises à un travail d'abréviation analogue à celui qui fut appliqué aux lettres ignatiennes. On aura abrégé le texte des livres I-VI des Constitutions Apostoliques pour constituer celui plus bref de la Didascalie, et le texte du livre VII pour former celui de la Didache” (Ib., 410).

(78) "En un mot, la plus grave objection que 1'on fera à la thèse du P. Weijenborg, si considérable et si méritoire qu'elle soit à tant d'égards, c'est qu'elle repose au fond sur une pétition de principe. L'auteur commence par poser une thèse, puis il interprète les textes, non sans quelques coups de pouce, dans le sens de cette thèse, et il conclut que la thèse a été demontrée... Au reste aucune des remarques de détail n'est vraiment concluante par elle-même: comment leur somme le seraitelle?" (P. Th. Camelot, Bibl 51(1970)563s). "Ohne Zweifel steckt hinter der umfangreichen Untersuchung viel Arbeit und Kenntnis. Schade, dass sie nicht in den Dienst einer fruchtbareren Methode gestellt wurden" (O Perler, Die Briefe des Ignatius von Antiochien. Frage der Echheit -neue, arabische Übersetzung, FZPhTh 18(1971)381-396, p. 395). "No va poi dimenticato, come fa l'autore, l'argomento che cioè generalmente parlando fra due recensioni dubbie quella più sobria e breve ha maggiori garanzìe di autenticità che quella più abbondante e verbosa" (I. Ortiz de Urbina, OChP 37(71)500).

(79) Où en est la question d'Ignace d'Antioche? Bilan d'un siècle de recherches 1870-1988, en ANRW, II, 27, 1, pp. 359-484.

(80) “De l'avis général des historiens et des patrologues qui se sont prononcés jusqu'à présent, il n’y a pas lieu, au vu des travaux de Weijenborg, Joly et Rius-Camps, d'abandonner les conclusions établies par les philologues du XIXe siècle" (op. cit., 379s). Muchas críticas han mostrado la fragilidad de los argumentos de estos contestarios. "En ce qui concerne la tradition manuscrite des Lettres et ses diverses recensions, un consensus définitif paraît s'être établi, bien que certains points de détail demeurent en discussion" (op. cit., 471).

(81) Respecto al rechazo de las tesis de estos dos autores, puede verse F. Bergamelli, 'Fede di Gesù Cristo' nelle lettere di Ignazio di Antiochia, Sal 66(2004)649-664, n. 5.

(82) Der paradox Eine. Antignostischer Monarchianismus im zweiten Jahrhundert, mit einem Beitrag von Markus Vinzent (Supplements to Vigiliae Christianae, 50), Leiden 1999. Ya antes había publicado lo más importante de su posición respecto a Ignacio en Thesen zur Echheit und Datierung 
monarquiana antivalentiniana de Noeto (83) y serían de la segunda mitad del s. II (años 165-175). Compara los dos himnos cristológicos de Ignacio (E 7, 2 y P 3, 2) con las reglas de fe de Noeto (84). Le llaman la atención las fórmulas teopasquitas de Ignacio, como sangre de Dios (85) El Logos eterno que sale del Padre es Dios mismo revelado en Jesucristo y no una segunda persona divina preexistente. La unidad del Padre y Cristo consiste en el Espíritu, que les es idéntico. Cristo es un espíritu divino en carne (86). Pero, contrariamente, nos preguntamos, ¿por qué los

der sieben Briefe des Ignatius von Antiochien, en ZAC 1(1997)44-72. A esta presentación replicará rápidamente en la misma revista A. Lindemann (Antwort auf die "Thesen zur Echheit und Datierung der sieben Briefe des Ignatius von Antiochien" (ZAC 1(1997)185-194)). Sin entrar en lo de Noeto, que declara no ser de su competencia, Lindemann enumera una serie de contradicciones, debilidades o cosas que prueban lo contrario en la argumentación de Hübner y termina diciendo en una nota que muchas cosas hablan por una fecha alternativa y temprana de composición. Igualmente G. Schöllgen (Die Ignatianen als pseudepigraphisches Briefcorpus. Anmerkung zu den Thesen von Reinhard M. Hübner, ZAC 2(1998)16-25), quien concluye: "so wie Hübner die Fälschung rekonstruiert, ist sie weniger plausibel als die Annahme der Authentizität" (ib., 25). Porque, entre otras cosas, "Widersprüche und besonders Mangelnde Plausibilität sprechen in der Regel eher gegen die Annahme einer Fälschung" (ib., 21). "Mir ist im zweiten Jahrhundert weder ein Prophet noch ein Märtyrer bekannt, der es mit der Autorität seiner Geistbegabung geschafft hätte, disziplinäre Neuerungen durchzusetzen" (ib., 18). En la misma línea de lo poco plausible de la hipótesis de Hübner, reacciona M. J. Edwards (Ignatius and the Second Century; An Answer to R. Hübner, ZAC 2(1998)214-226), porque las cartas de Ignacio no corresponden al ambiente del siglo II tardío. El argumento del silencio (expresiones que en época temprana solo aparecen en Ignacio) es de poco peso, porque se perdió buena parte de la literatura de esa época, etc. Descuida la comparación con muchos textos del N. T. y con las Pastorales (p. ej.: 1Tm 3, 16; Rm 1, 3s; Tt 2, 13; 1 Co 4, 1), y con el tema del misterio que estaba oculto desde los siglos y generaciones. Es más plausible que Ignacio haya influenciado a Valentín y Noeto, y no al revés. "Standing as he does midway between Paul and Valentinus, Ignatius likes to enhance the Apostle's metaphors, but not to the point of fantasy" (ib., 225). "Silence is thus the medium of God's work in the World, and it is possible, even probable, that the silence of Magnesians 8,2 is the preparation of the birth of Christ" (ib., 224).

(83) En contra arguye R. Staats: "Nun war aber Noet von Smyrna erster oder zweiter Nachfolger des Polykarp von Smyrna, welcher selbst Gastgeber, Briefempfänger und Verehrer des Ignatius in Smyrna gewesen war. Es ist daher wahrscheinlicher, dass Noet auch einmal aus der stolzen Ignatius-Tradition seiner eigenen Kirche schöpfte, als dass ungekehrt alle Ignatianen von einem Noet-Schüler zusammengebastelt wurden" (Ignatius und der Frühkatholizismus -Neues zu einem alten Thema, Verkündigung und Forschung 48(2003)80-92, p. 88). Respecto a anacronismos, responde que algunas expresiones más bien calzan con el temprano siglo segundo, que con el tardío. Finalmente H. J. Vogt (Bemerkungen zur Echheit der Ignatiusbriefe, ZAC 3(1999)50-63) refuta punto por punto (M 8, 2; E 7, 2; P 3, 2; autorresurrección en Sm 2) los argumentos probatorios de Hübner. Así, entre otras cosas, M 8, 2 se refiere, según él, a la economía, y en los

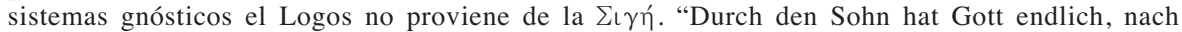
langem Schweigen, wieder gresprochen" (ib., 52). Muestra lo artificial del manejo de los himnos por Hübner, y el fondo ignaciano y neotestamentario de estos.

(84) "Eph 7,2 und Pol 3, 2 sind der Sache nach Stücke antignostisch eingesetzter Glaubensregeln. Die inhaltlichen Aussagen und den antithetischen Bau hat der Verfasser der Ignatianen weitgehend aus Noëts Glaubensregel übernommen, aber doch souverän neu geformt, wobei er in Pol 3, 2 selbständig auf valentinianisches Material zurückgreift" (Der paradox Eine, p. 202). Las antítesis provendrían de un mismo texto de Noeto, e Ignacio las habría dividido en dos textos (ib., 160).

(85) E 1, 1, etc. "Produckt der Polemik sind auch die theopaschitischen Formulierungen vom '(Todes)leiden Gottes' und 'Blut Gottes'. Sie setzen die gnostische Leugnung des Leidens des im wahren menschlichen Fleische gekommenen einen Gottes voraus. Wie die ausdrückliche Bezeichnung Jesu Christi als '(der) Gott' oder 'unser Gott' sind sie vor ca. 150/160 nicht nachweisbar" (Der paradox Eine, 203).

(86) "Der im Fleische gekommene Gott ist der einzige. Der ewige Logos, der aus dem Vater hervorgeht, ist der in Jesus Christus offenbare Gott selbst, nicht etwa eine zweite vorzeitliche göttliche Gestalt ('Person'), die neben dem Vater existierte. Die Einheit von Vater und Sohn 
adversarios de Ignacio se parecen a los docetas de las cartas de Juan, y no tienen referencias más claras al sistema de Valentín? (87) Las fórmulas teopasquitas están contextuadas en el temperamento o experiencia 'mística' de Ignacio y no son lejanas a 1Co 2, 8, Tt 2, 13s, etc. Los himnos cristológicos de Ignacio son anteriores a sus cartas (88) y son diferentes entre sí, aunque los dos contrasten lo pasible con lo impasible (89). El gozne del himno de E es predominantemente la pasión y resurrección del Señor (90); en cambio, el de Pol es la encarnación. En ese sentido, el primero corresponde a una cristología muy primitiva, al paso del Cristo carnal a espiritual por la resurrección, no muy distante de Rm 1, 3s (véase 1Tm 3,16) (91). Achacarle "modalismo" a Ignacio, es demasiado (92). Puede verse la paciente refutación de H. J. Vogt (93). No por proclamar "un solo Dios" (94), (también lo hace Jn y nosotros), el Hijo y el Padre son el mismo. "El único Jesucristo procedió de un Padre y para uno es y a uno se dirigió" (M 7, 2). En una palabra, Hübner muestra bastante unilateralidad y cierto simplismo (95).

(Gott und Jesus Christus) besteht im Geist, der mit Gott identisch ist. Das christologische Schema ist so einfach wie bei der Mehrzahl der christlichen Autoren dieser Zeit: Jesus Christus ist göttlicher Geist in menschlichem Fleisch und deswegen Gott und Mensch" (Ib., 203). "Seine Absicht ist es, durch die Propagierung des monepiskopalen Amtes in einer Hierarchie göttlichen Rechts die Einheit der katholischen Gemeinden im Glauben an den einen Erlöser-Gott, den ans Kreuz genagelten Unsterblichen, gegenüber den häretischen Abspaltungen zu begründen und zu festigen. Er benutzt zur Durchsetzung seines Anliegens eine Stimme mit unanfechtbarer, das heisst göttlicher Autorität, die des geistbegabten Martyrers, welche um diese Zeit höchstes Ansehen geniesst, und lässt diesen Anspruch wiederum durch einen hochverehrten Martyrer und Bischof, Polykarp von Smyrna, beglaubigen" (ib., 204).

(87) ¿No bastaría con una oposición a Cerinto, si se profundizan los dichos de Ignacio sobre la unidad de Cristo y su referencia al bautismo y cruz en E 18,1 s?

(88) Difícilmente un prisionero compone un himno al dictar una carta.

(89) No en el mismo orden.

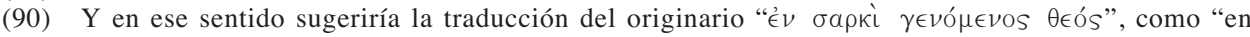
carne llegado a ser Dios" (gozne de la pasión y resurrección), y no como "Dios llegado a ser en carne" (gozne de la encarnación), conservando así la secuencia de los otros versos. Pero no estoy diciendo que Ignacio, con su acentuación de la divinidad de Cristo, que fue progresiva en los tiempos del Nuevo Testamento culminando en Ignacio, lo haya entendido así. Refiriéndose a este himno afirma Vogt (Bemerkungen, 56): "seine Perspektive ist also in diesen antithetischen Ausdrücken die des Aufstiegs vom Menschlichen ins Göttliche". Esto es lo contrario a lo de los noetianos.

(91) Véase Hch 2, 36; Sm 1, 1; E 20, 2.

(92) Cf. S Zañartu, Aproximaciones a la cristología, 119-121.

(93) Vertreten Ignatius-Briefe Patripassianismus?, ThQ 180(2000)237-251. Concluye este autor: "Es gibt keine Einzelaussage bei Ignatius, die sicher patripassianisch wäre oder sicher seine Abhängigkeit von Noet bewesein würde; und der Gesamtinhalt der Ignatianen spricht dagegen. Damit ist natürlich die Echheit der Briefe genausowenig positiv bewiesen..." (ib., 251).

(94) M 8,2. Respecto la unidad de Cristo puede verse: E 7, 2; 15, 1; M 7, 2; 9, 1; R Inscr; F 4.

(95) La contribución de M. Vinzent en el libro de Hübner ("Ich bin kein körperloses Geistwesen".

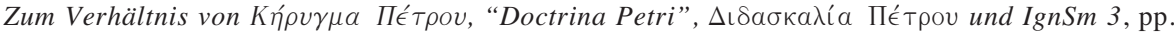

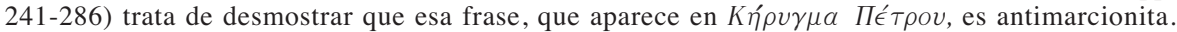
Le responde H. J. Vogt (Sind die Ignatius-Briefe antimarkionitisch beeinflusst?, ThQ 181(2001)1-19, p. 19): "Nachdem er schon im Trallianer-Brief den Doketen, die alles leibliche Leben des Heilandes und erst Recht sein Leiden als blossen Anschein betrachteten, vorgeworfen hatte, sie selber führten eine blosse Scheinexistenz, steigert er sich noch im Brief an die Smyrnäer und verheisst den Doketen eine zukünftige körperlose dämonische Seinsweise. Deshalb fasst er das lange Jesus-Wort von Lk 24, 39 in die knappe und zugleich überzeugend gegen eben diese Doketen gerichtete Form: "Fasst mich an, betastet mich und seht, dass ich kein körperloser Dämon bin”. Hier zeigt sich wieder die... gerühmte Spontaneität und Assoziationskunst des Igna- 
T. Lechner (96) cree que los problemas puestos por Joly no han sido satisfactoriamente respondidos. En una muy erudita primera parte postula que la carta de Policarpo a los Filipenses fue interpolada por el mismo autor tardío de lo ignaciano, pero no convence (97). A mi parecer, muestra también arbitrariedad al tratar de explicar cómo llegó Eusebio a ponerlo en la lista como segundo obispo de Antioquía (98), martirizado bajo Trajano. En una interesante segunda parte analiza extensamente el himno al astro y su contexto (E 16-20). Se detiene sobre todo en la fórmula de fe de E 18, 2 y en E 19 (99). Cree que es una réplica al valentinismo, sobre todo marcosiano. El himno sería una especie de parodia. En vez de que el Salvador pneumático sea engendrado por la totalidad de los eones que han recobrado el reposo, el Salvador de Ignacio es engendrado en el vientre de María y el astro que lo manifiesta produce la confusión (тapaxń) de los eones. En vez de ser todos los eones iguales, el astro de Jesús es desemejante y extraño (100). Antes, en E 18, 2, presenta el bautismo para purificar el agua por la pasión, en vez de ser este el momento de unión del salvador pneumático con Jesús. Esto ya estaba excluido porque nuestro Dios fue el llevado en el vientre de María y dado a luz. Jesús no pasó por María sin tomar nada de ella, sino que éкvофори́ $\theta \eta$ (101). Estas son algunas de

tius. Das ist plausibel und nachvollziehbar. Eine einleuchtendere Erklärung für das Entstehen dieses ausserbiblischen Jesus-Wortes wird sich nicht finden lassen. Ignatius hat eine Vorlage weder gebraucht noch gehabt; und von einem Markion-Gegner beeinflusst er ist auch nicht". Y

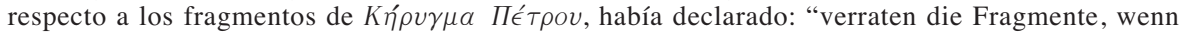
sie ohne diese falsche Perspektive untersucht werden, keinen Antimarkionismus (ib., 16).

(96) Ignatius adversus Valentinianos? Chronologische und theologiegeschichtliche Studien zu den Briefen des Ignatius von Antiochien (Supplements to Vigiliae Christianae, 47), Leiden 1999.

(97) Así, por ejemplo, presenta la explicación de una deficiente traducción latina, donde en Flp 13, 2 se usaría el presente en vez del pasado, y la rechaza, sin fijarse que ese mismo tipo de mala traducción consta en Flp 9, 1, como ya vimos a propósito de Joly. Por lo demás, ¿tan inhábil era el interpolador que no se percató de la tensión que introducía entre presente y pasado?

(98) Cf. también Orígenes, In Lucas Hom VI. Cerca de la conclusión, dice así Lechner: "Falls aber schon (wie in Rom) gegen Ende des 2./ Anfang des 3. Jhs. in Antiochien eine offizielle Bischofsliste vorhanden war, dann fragt man sich selbsvertändlich, wie es dazu kommen konnte, dass Ignatius in der antiochenischen Bischofsliste als zweiter Bischof der antiochenischen Gemeinde geführt wurde, obwohl dieser Ignatius von Antiochien (die These der vorliegeden Arbeit vorausgesetzt) niemals existiert hat". Las listas de obispos surgen, según él, por el 160 para mostrar la sucesión (y la ortodoxia) contra la amenaza de los herejes. Prosigue nuestro autor: "Geht man einmal davon aus, dass die Entwicklung in Antiochien ähnlich verlaufen ist wie in Rom, dann kommen unter der Voraussetzung, dass die Ignatianen um 165-175 verfasst worden sind, zwei Motive für die Integration des 'Ignatius von Antiochien' in die antiochenische Diadoche in Betracht. Einmal der klare antihäretische Charakter der Ignatianen, der dem antihäretischen Zweck der Listen nur förderlich sein konnte, zum anderen die Hochschätzung des Bischofsamtes in den Ignatianen, die dem episkopalen Prinzip der Bischofslisten vollkommen entsprach" (ib. 111s).

(99) "Der Schrei Eph. 19, 1 dokumentiert also das Wirken des Geistes und letztlich kann dieser Schrei kein anderer sein als der Schrei der Elisabeth (Lk. 1, 42)" (Ib., 259). Cf. 1Co 2, 6-8.10-16.

(100) "Die Interpretation von Eph. 19, 1-3 hat gezeigt, dass der gesamte Abschnitt einen polemischen Kommentar zum valentinianischen Mythos darstellt, und zwar konkret zu jener Szene, in welcher der pneumatische Erlöser von den Äonen im Pleroma erzeugt wird. Diese Szene hat Ignatius im Sternhymnus kunstvoll nachgestaltet und radikal umgedeutet... Treffender kann man die valentinianische Geburtsszene gar nicht parodieren... Berücksichtigt man zudem die Ergebnisse der Untersuchung zur Glaubensformel Eph. 18, 2, dann kann man festellen, dass alle Eph. 18-19 behandelten christologischen Themen präzise den Vorgaben des valentinianischen Mythos entsprechen" (ib., 297s).

(101) E 18, 1-20, 1 estaría construido según el esquema del himno helenístico en prosa (cf. ib., II, cap. 6,3$)$. 
sus conclusiones después de presentar todo paralelo posible con los valentinianos (102). Pero lo que nunca se plantea este autor es qué docetismo (103) existió antes de Valentín, o contra quién combaten las cartas de Juan. Curiosamente copia dos pasajes de la 1Jn que trae Ireneo en Adv Haer III, 16, 5.8, para refutar justamente a los que dividen al Señor, a los gnósticos (104). Con todo, obviamente no dice que hayan sido escritos por Juan contra los valentinianos, como sí lo afirma de Ignacio. Yo no creo se deba esperar hasta Valentín para que alguien distinga entre Jesús y el Cristo, o niegue que el Cristo vino en carne (105). Igualmente la explicitación de la divinidad de Cristo va 'in crescendo' a lo largo del N. T., lo que culminaría en Ignacio. Al concluir su recensión de estos dos últimos contradictores de la recensión media, B. Sesboüé expresa: “¿Estaremos en presencia de una 'revisión desgarradora'? ¿Conviene aceptar sin más sus conclusiones? El unilateralismo patente de los dos estudios hace pensar en alegatos de abogados que acumulan todos los argumentos a favor de sus tesis, sin tener en cuenta nada de los datos opuestos" (106).

(102) Respecto al controvertido pasaje de E 19, 1- 3, me atravería a repetir el fondo de lo ya dicho en mi tesis (p. 147 n. 35): "Creo que se trata de tradiciones, fundamentalmente, judeocristianas (cf. J. Daniélou, Théologie du Judéo-Christianisme (Desclée 1958), 228-247)". Pero estas se pueden también encontrar, transformadas, en los gnósticos, por ejemplo en Excerpta ex Theodoto, 74. Recordemos que solo en E 18, 2 Ignacio habla de Jesús el Cristo.

(103) Un docetismo puro, es decir un ser divino solo con apariencia externa humana, no es tan fácil de encontrar (puede verse, p. ej., E. M. Yamauchi, The Crucifixion and Docetic Christology, ConcordiaThQ 46(1982)1-20 , p. 5ss; A. Grillmeier, Jesus der Christus im Glauben der Kirche. I: Von der Apostolischen Zeit bis zum Konzil von Chalcedon (451), Freiburg 1979, $2^{\mathrm{a}}$ ed., pp.

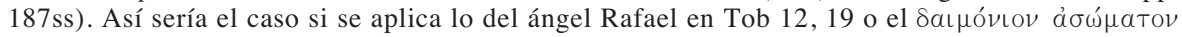
que temían ver los discípulos en el resucitado (Sm 3, 2; cf. Lc 24, 39; Orígenes, De Principiis, Praef 8; Jerónimo, In Is, I, 18, prol.) Sin querer entrar en una investigación histórica sobre los orígenes del docetismo, permítaseme una simple reflexión de marco teórico. Es obvio que los que vieron y crucificaron a Jesús no dudaron de su carne y de sus huesos. Pero, ante el escándalo de la cruz, muchos no vieron en esta carne crucificada, la fuerza divina que poseyó a Jesús en su manifestación taumatúrgica como Cristo durante su vida. Así algunos pudieron llegar a decir que ese Cristo divino no padeció, sino su apariencia, es decir el Jesús que fue sepultado. De ahí que distinguieran entre Jesús y Cristo. En una palabra, teóricamente no se ve que un adopcionismo no pueda derivar en un docetismo. Para esto no hay que esperar tantos años. Respecto al docetismo, M. Slusser, defendiendo la definición de Baur y las aplicaciones de Ireneo, dice: "I would add that the second view no less than the first (docetismo puro) holds that Christ was man only in appearance, for it says that not Christ but another, the earthly Jesus, was the man" (Docetism: A Historical Definition, Second Century 1(1981)163-172, p. 172).

(104) 1 Jn 2, 18-22 y 5, 1 en pp. 187s. No tiene más citas de las cartas de Juan.

(105) Cf. 1Jn 4, 2s; 5, 1.5s; 2Jn 7. Dice Grillmeier respecto a Ignacio: "Wie bei Johannes ist die Einheit der zwei Seinsweisen in Christus, Logos und Sarx, voller Spannung. Auf beiden Polen liegt ein starker Akzent, vor allem angesichts der Aufspaltungstendenzen der Doketen und der anderen Häretiker, die schon zu lebzeiten des Verfassers von 1 Joh auf eine 'Auflösung' Christi hinarbeiteten (1Joh 4, 3)" (op. cit., 199).

(106) “Serions-nous en présence d'une 'revision déchirante'? Convient-il d'accepter sans plus ces conclusions? L'unitéralisme patent des deux études fait penser à des plaidoiries d'avocats qui accumulent tous les éléments en faveur de leur thèse sans tenir aucun compte des données opposés" (RSR 90(2002)253). Y añade más adelante: "Car il faut aussi considérer les difficultés que pose la datation entre 165 et 175 . L'une d'entre elles, qui n'a pas été prise en compte, est le rapport des-Lettres ignatiennes au NT. L'opinion plus largement reçue tient qu'Ignace se réfère à la tradition orale et non à des textes évangéliques écrits. Comment se fait-il qu'à cette époque tardive l'auteur ne se serve pas du NT à la manière d'un Justin, pour ne pas dire d'un Irenée? La polémique antidocète dans les Lettres d'Ignace a toujours été reconnue, sans être considérée 
Como muestra de que la polémica sobre la autenticidad de la recensión media no ha terminado, basta con aludir al reciente y débil artículo de C. y A. Faivre (107). Ignacio, que no pretende hablar como un apóstol, se habría parapetado detrás de su calidad de inspirado destinado al martirio para promover al obispo a quien todos deben someterse (108). En sus procedimientos muestra cierto parecido con Pablo (109). Exceptuada la carta a los romanos, su determinación, casi obsesionante, es obtener la sumisión absoluta al obispo (110).

Vista la debilidad de las objecciones de estos autores contra la autenticidad de la recensión media, y que una redacción tardía abre más problemas que los que intenta solucionar, es mejor permanecer en el predicamento de la autenticidad de la recensión media mientras no se pruebe lo contrario. Más aún, no ser derribada por tanto ataque ingenioso recibido (111), más bien confirma su solidez. Los ataques ni siquiera han detenido los numerosos estudios que se siguen haciendo tranquilamento sobre su teología, etc. Así C. Munier (112) concluye su valioso trabajo con una síntesis temática que implica una época temprana para su composición. El ataque a la autenticidad de la recensión media ha sido el segundo martirio de Ignacio, que quizás nunca va a cesar totalmente.

\section{RESUMEN}

El autor presenta la hipótesis de J. Rius-Camps con cierto detalle y la descarta. A continuación pasa a las objeciones de R. Joly, terminando con una alusión a R. Weijenborg. El segundo tramo está dedicado a las hipótesis de R. M. Hübner y T. Lechner. La debilidad de las objeciones de estos autores vuelve a confirmar, en cierta forma, la autenticidad de la recensión,

comme incompatible avec une datation haute. La récusation systématique de tous les témoignages anciens est-elle au-dessus de toute instance?" (ib.).

(107) Modes de communication et rapports de pouvoir dans les Lettres d'Ignace d'Antioche, RivStorCr 3(2006)59-82.

(108) "Il est martyr, ou plutôt il va au martyre, mais cet anéantissement programmé lui permet de justifier son innovation institutionnelle par des affirmations répétitives et imbriquées qui laissent soupçonner un processus social proche de ce que René Girard analyse dans ses travaux. Ignace est lui-même le bouc émissaire qui se livre volontairement à la mort pour que le groupe chrétien puisse vivre unifié autour de l'évêque et de la triade ministérielle" (ib., n. 12).

(109) “On retrouve encore chez Ignace la même humilité et la même transparence à l'autorité divine que chez Paul, la même façon de se démarquer de l'usage rhétorique d'une prudente raison au profit de 1'inspiration" (ib., 65).

(110) “Nous voyons qu'il envisage tous les aspects et qu'il met au service de cette soumission aussi bien les procédés littéraires que les raisonnements théologiques, aussi bien sa personne que les ministres de l'Église et, preuve suprême de sa conviction, aussi bien sa volonté que sa chair. La mise en scène du corpus aussi bien que le choix du genre littéraire, tout concourt à asseoir l'autorité d'un monoépiscopat auquel sont soumis les presbytres et, en dernier rang, les Sıákovol... L'auteur cherche avant tout, au travers d'une mystique et d'une symbolique, à mettre en rapport réalité divine et réalité ministérielle, et -surtout- à assurer l'unité de la communauté autour de la soumission à un seul évêque... C'est au travers du martyre, que s'accomplissait le paradoxe du ministère chrétien. En se plaçant en de ça du monde et au-delà de l'abaissement du martyre, Ignace gomme cette tension au travers de laquelle le plus grand doit se faire serviteur. Ceci lui laisse le champ libre pour mettre en avant une hiérarchie de soumission qu'il présente désormais comme un absolu" (ib., 81).

(111) En ellos se ha invertido mucho trabajo científico, pero no ha campeado el sentido común.

(112) Op. cit., 470-484. 
que habrá de ser tenida como verdadera mientras no se pruebe lo contrario. Este artículo es complementario a otro en que se revisó la literatura ignaciana de los últimos decenios.

Palabras clave: autenticidad, Ignacio de Antioquía, estudios recientes.

\begin{abstract}
The author presents the hypothesis of J. Rius-Camps in some detail and rejects it. Then he continues to the objections of $R$. Joly, concluding with an allusion to R. Weijenborg. The second part is dedicated to the hypothesis of R. M. Hübner and T. Lechner. The weakness of the objections of these authors again confirm, in some form, the authenticity of the middle recension, which should be taken as true as long as it is not proven otherwise. This article is complementary to another in which he reviewed the Ignatian literature over the past decades.
\end{abstract}

Key words: authenticity, Ignatius of Antioch, recent studies. 